\begin{tabular}{|c|c|c|}
\hline \multirow{3}{*}{$\begin{array}{r}\text { Case Reports in } \\
\text { Gastroenterology }\end{array}$} & \multirow{2}{*}{\multicolumn{2}{|c|}{ Case Rep Gastroenterol 2014;8:1-6 }} \\
\hline & & \\
\hline & $\begin{array}{l}\text { DOI: 10.1159/000358046 } \\
\text { Publisned onine: January 8, } 2014\end{array}$ & $\begin{array}{l}\text { (c) } 2014 \text { S. Karger AG, Basel } \\
\text { 1662-0631/14/0081-0001 } \$ 39.50 / 0 \\
\text { www.karger.com/crg }\end{array}$ \\
\hline & \multicolumn{2}{|c|}{$\begin{array}{l}\text { This is an Open Access article licensed under the terms of the Creative Common } \\
\text { Attribution-NonCommercial } 3.0 \text { Unported license (CC BY-NC) (www.karger.com/OA } \\
\text { license), applicable to the online version of the article only. Distribution permitted for non } \\
\text { commercial purposes only. }\end{array}$} \\
\hline
\end{tabular}

\title{
Gastrointestinal Obstruction due to Solitary Lymph Node Recurrence of Alpha-Fetoprotein-Producing Gastric Carcinoma with Enteroblastic Differentiation
}

\author{
Takumi Yamabuki $^{\mathrm{a}}$ Makoto Omi $^{\mathrm{a}}$ Atsuya Yonemori ${ }^{\mathrm{a}}$ Kenjiro Misu ${ }^{\mathrm{a}}$ \\ Hitoshi Inomata $^{a}$ Yukie Abiko ${ }^{b}$ Michio Mori ${ }^{b}$ Kazuyoshi Nihei ${ }^{a}$ \\ ${ }^{a}$ Department of Surgery, Kushiro Red Cross Hospital, Kushiro, and ${ }^{b}$ Department of \\ Pathology, Sapporo General Pathology Laboratory, Sapporo, Japan
}

\section{Key Words}

Gastrointestinal obstruction - Lymph node recurrence - Alpha-fetoprotein-producing gastric carcinoma

\begin{abstract}
We report an unusual case of alpha-fetoprotein (AFP)-producing gastric carcinoma with enteroblastic differentiation. A 75-year-old woman was admitted to our hospital with occasional upper abdominal discomfort. We performed gastroscopy and observed a type 2 tumor, primarily in the pyloric region. Histological examination of biopsies confirmed gastric adenocarcinoma. Based on these findings, we diagnosed gastric adenocarcinoma and performed laparoscopic distal gastrectomy with lymph node dissection. Histological examination revealed an invasive lesion composed of adenocarcinoma with a tubulopapillary growth pattern. Tumor cells were cuboidal in shape with characteristically clear cytoplasm rich in glycogen. Two regional lymph node metastases were seen microscopically. Immunohistochemically these cells were positive for AFP, carcinoembryonic antigen, caudal-type homeobox transcription factor 2 and common acute lymphoblastic leukemia antigen. The final diagnosis was AFP-producing gastric carcinoma with enteroblastic differentiation. 26 months after initial surgery, the patient was readmitted to our hospital for gastrointestinal obstruction due to lymph node recurrence.

(c) 2014 S. Karger AG, Basel
\end{abstract}

T. Yamabuki, MD, PhD

Department of Surgery

National Hospital Organization Hakodate Hospita

18-16 Kawahara-cho, Hakodate 041-8512 (Japan)

E-Mail bukiyama@themis.ocn.ne.jp 


\section{Introduction}

Alpha-fetoprotein (AFP) is a well-known tumor marker of hepatocellular carcinoma and germ cell tumors. Bourreille et al. [1] reported the first case of AFP-producing gastric cancer with liver metastasis in 1970 . The tumor shows an aggressive clinical course, with frequent metastasis to the liver, lymph nodes and other organs. Here, we describe the clinical course and histopathological aspects of an unusual case of AFP-producing gastric carcinoma with enteroblastic differentiation, and review the relevant literature.

\section{Case Report}

A 75-year-old woman with a history of diabetes mellitus, hyperlipidemia and osteoporosis consulted her local physician for occasional upper abdominal discomfort. She was referred and admitted to our hospital for evaluation and treatment. No abdominal tumor mass or superficial lymph nodes were palpable. Routine laboratory findings were unremarkable, with the exception of slightly elevated serum AFP $(10.5 \mathrm{ng} / \mathrm{ml})$. Gastroscopy revealed a 20 -mm type 2 tumor, primarily in the pyloric region. Histological examination of gastroscopic biopsies confirmed gastric adenocarcinoma (moderately differentiated tubular adenocarcinoma), but no detailed information was obtained. Barium enema confirmed a type 2 tumor in the pyloric region. No obvious lymph node metastasis or remote metastasis was observed on contrast-enhanced computed tomography (CT).

Thus, with a provisional diagnosis of gastric adenocarcinoma, we performed laparoscopic distal gastrectomy with lymph node dissection. Macroscopically, the type 2 tumor was located near the pylorus and measured $20 \times 15 \mathrm{~mm}$ (fig. 1a). It invaded vertically into the muscularis propria, and two regional lymph node metastases were observed microscopically. Histological examination demonstrated the presence of adenocarcinoma with a tubulopapillary growth pattern (fig. 1b). Tumor cells were cuboidal in shape with characteristically clear cytoplasm. Periodic acid-Schiff (PAS) stain showed that the clear cytoplasm was almost filled with fine granular glycogen (fig. 1c). The tumor cells were negative in mucin in either alcian blue-PAS stain, but also in the immunohistochemistry for MUC2 (goblet cell mucin) or MUC5AC (foveolar mucin).

Immunohistochemically, tumor cells were positive for AFP (fig. 2a), carcinoembryonic antigen (CEA) (fig. 2b), caudal-type homeobox transcription factor 2 (CDX2) (fig. 2c) and common acute lymphoblastic leukemia antigen (CD10) (fig. 2d). AFP was mainly expressed in the cytoplasm whereas CEA was positive in the apical surfaces of tumor cells. CDX2 was expressed strongly in the tumor cell nuclei. CD10 was positive in the luminal surfaces in some tumor cells. The tumor was immunohistochemically negative in synaptophysin, chromogranin A and CD56 (NCAM), though a few chromogranin A and few synaptophysinpositive neuroendocrine cells were found scattering among clear carcinoma cells. Human chorionic gonadotropin was not found in tumor cells. The final diagnosis was AFP-producing gastric carcinoma with enteroblastic differentiation. Lymph node metastases showed similar histological and immunohistochemical results as the primary site.

The patient had an uneventful postoperative course, and AFP levels normalized to 3.7 $\mathrm{ng} / \mathrm{ml}$. She was followed without adjuvant chemotherapy because of her advanced age. However, 15 months after the initial surgery, serum levels of AFP increased to $279.4 \mathrm{ng} / \mathrm{ml}$, and fluorodeoxyglucose positron emission tomography (FDG-PET) revealed No. 8p lymph node recurrence (fig. 3a). Therefore, chemotherapy combining cisplatin (CDDP) and etoposide (VP-16) was conducted for six courses. The size of lymph node recurrence initially 
Yamabuki et al.: Gastrointestinal Obstruction due to Solitary Lymph Node Recurrence of Alpha-Fetoprotein-Producing Gastric Carcinoma with Enteroblastic Differentiation

decreased, but she consulted our hospital for upper abdominal pain and vomiting 26 months after the initial surgery. A CT scan revealed gastrointestinal obstruction near the anastomotic site of gastroduodenostomy due to No. 8p lymph node recurrence (fig. 3b). As it was difficult to continue chemotherapy, she underwent palliative gastrojejunostomy. The surgery temporarily restored adequate oral intake, but she received repeated blood transfusions for uncontrollable gastrointestinal bleeding, and serum levels of AFP increased to 8,634 ng/ml. 29 months after initial surgery, the patient died.

\section{Discussion}

AFP was initially identified in the human fetus and is normally produced in the fetal liver and yolk sac [2]. AFP is also an important marker for the detection of hepatocellular carcinoma and yolk sac tumors, and there have been numerous reports on patients with AFP-producing gastric carcinoma [3-7]. However, such tumors are rare, accounting for 2.7$5.5 \%$ of gastric cancer $[4,8]$, and the overall 5 -year survival rate is $11.6-28.4 \%$, which is poor in comparison with AFP-negative gastric carcinoma (45.0-52.8\%) [3, 4, 8]. A review of 270 patients with AFP-producing gastric carcinoma revealed that the tumors are characterized by frequent serosal invasion (75\%), lymph node metastasis (83\%), liver metastasis (33\%), stage III or IV disease (75\%) and noncurative surgery (48\%). Furthermore, survival is influenced by serum AFP levels, tumor size, serosal invasion, lymph node metastasis and liver metastasis, but independent prognostic factors are operative curability (curative vs. noncurative) and stage of disease (I, II vs. III, IV) [3].

The criteria for diagnosing AFP-producing gastric carcinoma depend on positive staining of primary lesions by immunohistochemical methods. Serum AFP levels are an uncertain factor. Several diseases, such as hepatitis, liver cirrhosis and hepatocellular carcinoma, also give high levels of serum AFP that are not related to gastric lesions. On the other hand, normal serum AFP levels alone cannot exclude an AFP-producing tumor; the incidence of AFP-producing early gastric carcinoma with normal serum levels is $0.54 \%$ [8].

Kodama et al. [9] studied 35 cases of gastric cancer associated with high serum AFP levels and found two histological features associated with immunohistochemical positivity for AFP - papillotubular carcinoma with clear cytoplasm and medullary carcinoma resembling hepatocellular carcinoma. They also reported that these two types of carcinoma usually showed mixed growth in the same tumor. In 1985, Ishikura et al. [10] proposed a new clinicopathological entity, hepatoid adenocarcinoma of the stomach, which produces large amounts of AFP and has morphologically and immunohistochemically distinct foci of hepatoid differentiation. In 1994, Matsunou et al. [11] reported two cases of AFP-producing gastric carcinoma with enteroblastic differentiation (AFP-producing clear cell gastric carcinoma), and the tumor characteristics were as follows: (1) columnar carcinoma cells growing primarily in tubulopapillary and glandular patterns; (2) abundant glycogen, but no mucin production in the clear cytoplasm; (3) gut hormone-containing cells scattered among clear carcinoma cells; (4) carcinoma cells producing oncofetal glycoproteins such as AFP and CEA; (5) ultrastructurally, carcinoma cells showing well-developed microvilli with core filaments, whose rootlets formed occasional terminal webs, consistent with absorptive epithelium of fetal intestine or enteroblastic differentiation.

Based on a study of nine cases of AFP-producing gastric carcinoma, Motoyama et al. [12] proposed that AFP-producing gastric carcinomas should be divided into three subtypes: (1) hepatoid type, (2) yolk sac type and (3) fetal gastrointestinal type. One case that was morphologically classified as fetal gastrointestinal type showed moderately differentiated 
tubular adenocarcinoma. Some tumor cells had clear cytoplasm, in which considerable levels of glycogen were identified. Serum AFP levels were relatively low. The fetal gastrointestinal type was thought to be equivalent to AFP-producing gastric carcinoma with enteroblastic differentiation [11].

To our knowledge, only two cases have been reported as AFP-producing gastric carcinoma with enteroblastic differentiation [11]. However, we found several reports on AFPproducing gastric carcinomas that were equivalent to AFP-producing gastric carcinoma with enteroblastic differentiation [12,13]. Morphologically, all cases of these tumors contained cells with clear cytoplasm and tubule formation.

As a new finding, CDX2 was expressed strongly in the tumor cell nuclei of the present case. CDX2 is an intestine-specific transcription factor that regulates both proliferation and differentiation of intestinal epithelial cells. CDX2 is expressed in intestinal-type gastric neoplasia [14]. The enterocytic nature of tumor cells was also suggested by the immunohistochemical evidence that some tumor cells expressed CD10 in the luminal surfaces. CD10 is a glycoprotein localized preferentially in the brush border of intestinal epithelium.

Serum AFP levels were slightly elevated in the present case $(10.5 \mathrm{ng} / \mathrm{ml})$. Similarly, serum AFP levels were relatively low in the two cases of AFP-producing gastric carcinoma with enteroblastic differentiation reported by Matsunou et al. [11] $(21.5 \mathrm{ng} / \mathrm{ml}$ and 371.7 $\mathrm{ng} / \mathrm{ml}$ ) and in a case of fetal gastrointestinal AFP-producing gastric carcinoma reported by Motoyama et al. [12] $(120 \mathrm{ng} / \mathrm{ml})$. Although further studies are necessary to confirm this, the present case suggests that serum AFP levels are not high in this disease. However, serum AFP levels will be elevated when tumor cells metastasize to other organs. In fact, serum AFP levels increased significantly to $279.4 \mathrm{ng} / \mathrm{ml}$ when lymph node recurrence was detected 15 months after initial surgery, and serum levels of AFP increased to $8,634 \mathrm{ng} / \mathrm{ml} 28$ months after initial surgery.

In the present case, gastrointestinal obstruction due to solitary lymph node recurrence was detected. To our knowledge, there have been no reports on gastrointestinal obstruction due to solitary lymph node recurrence by AFP-producing gastric carcinoma.

In summary, we have reported a case of gastrointestinal obstruction due to solitary lymph node recurrence of AFP-producing gastric carcinoma with enteroblastic differentiation. Further investigations are needed in order to establish optimal treatment approaches for this unusual tumor.

\section{Disclosure Statement}

The authors have no funding or conflicts of interest to disclose.

\section{References}

1 Bourreille J, Metayer P, Sauger F, Matray F, Fondimare A: Existence d'alpha foetoprotéine au cours d'un cancer secondaire du foie d'origine gastrique. Presse Med 1970;78:1277-1278.

2 Bergstrand CG, Czar B: Demonstration of a new protein fraction in serum from the human fetus. Scand J Clin Lab Invest 1956;8:174.

3 Adachi Y, Tsuchihashi J, Shiraishi N, Yasuda K, Etoh T, Kitano S: AFP-producing gastric carcinoma: multivariate analysis of prognostic factors in 270 patients. Oncology 2003;65:95-101.

4 Kono K, Amemiya H, Sekikawa T, Iizuka H, Takahashi A, Fujii H, Matsumoto Y: Clinicopathologic features of gastric cancers producing alpha-fetoprotein. Dig Surg 2002;19:359-365.

-5 Chang YC, Nagasue N, Kohno H, Taniura H, Uchida M, Yamanoi A, Kimoto T, Nakamura T: Clinicopathologic features and long-term results of alpha-fetoprotein-producing gastric cancer. Am J Gastroenterol 1990;85:1480-1485. 
Yamabuki et al.: Gastrointestinal Obstruction due to Solitary Lymph Node Recurrence of Alpha-Fetoprotein-Producing Gastric Carcinoma with Enteroblastic Differentiation

-6 Wakasugi T, Akamo Y, Takeyama H, Hasegawa M, Teranishi F, Manabe T: Solitary intraperitoneal recurrence of alpha-fetoprotein-producing gastric carcinoma: report of a case. Surg Today 2002;32:429-433.

7 Tsurumachi T, Yamamoto H, Watanabe K, Honda I, Watanabe S, Yamada S, Jingu K, Satomi D, Fujita M: Resection of liver metastasis from alpha-fetoprotein-producing early gastric cancer: report of a case. Surg Today 1997;27:563-566.

8 Chang YC, Nagasue N, Abe S, Taniura H, Kumar DD, Nakamura T: Comparison between the clinicopathologic features of AFP-positive and AFP-negative gastric cancers. Am J Gastroenterol 1992;87:321-325.

-9 Kodama T, Kameya T, Hirota T, Shimosato Y, Ohkura H, Mukojima T, Kitaoka H: Production of alphafetoprotein, normal serum proteins, and human chorionic gonadotropin in stomach cancer: histologic and immunohistochemical analyses of 35 cases. Cancer 1981;48:1647-1655.

10 Ishikura H, Fukasawa Y, Ogasawara K, Natori T, Tsukada Y, Aizawa M: An AFP-producing gastric carcinoma with features of hepatic differentiation. A case report. Cancer 1985;56:840-848.

11 Matsunou H, Konishi F, Jalal RE, Yamamichi N, Mukawa A: Alpha-fetoprotein-producing gastric carcinoma with enteroblastic differentiation. Cancer 1994;73:534-540.

12 Motoyama T, Aizawa K, Watanabe H, Fukase M, Saito K: Alpha-fetoprotein producing gastric carcinomas: a comparative study of three different subtypes. Acta Pathol Jpn 1993;43:654-661.

-13 Fujii H, Ichikawa K, Takagaki T, Nakanishi Y, Ikegami M, Hirose S, Shimoda T: Genetic evolution of alpha fetoprotein producing gastric cancer. J Clin Pathol 2003;56:942-949.

14 Park do Y, Srivastava A, Kim GH, Mino-Kenudson M, Deshpande V, Zukerberg LR, Song GA, Lauwers GY: CDX2 expression in the intestinal-type gastric epithelial neoplasia: frequency and significance. Mod Pathol 2010;23:54-61.
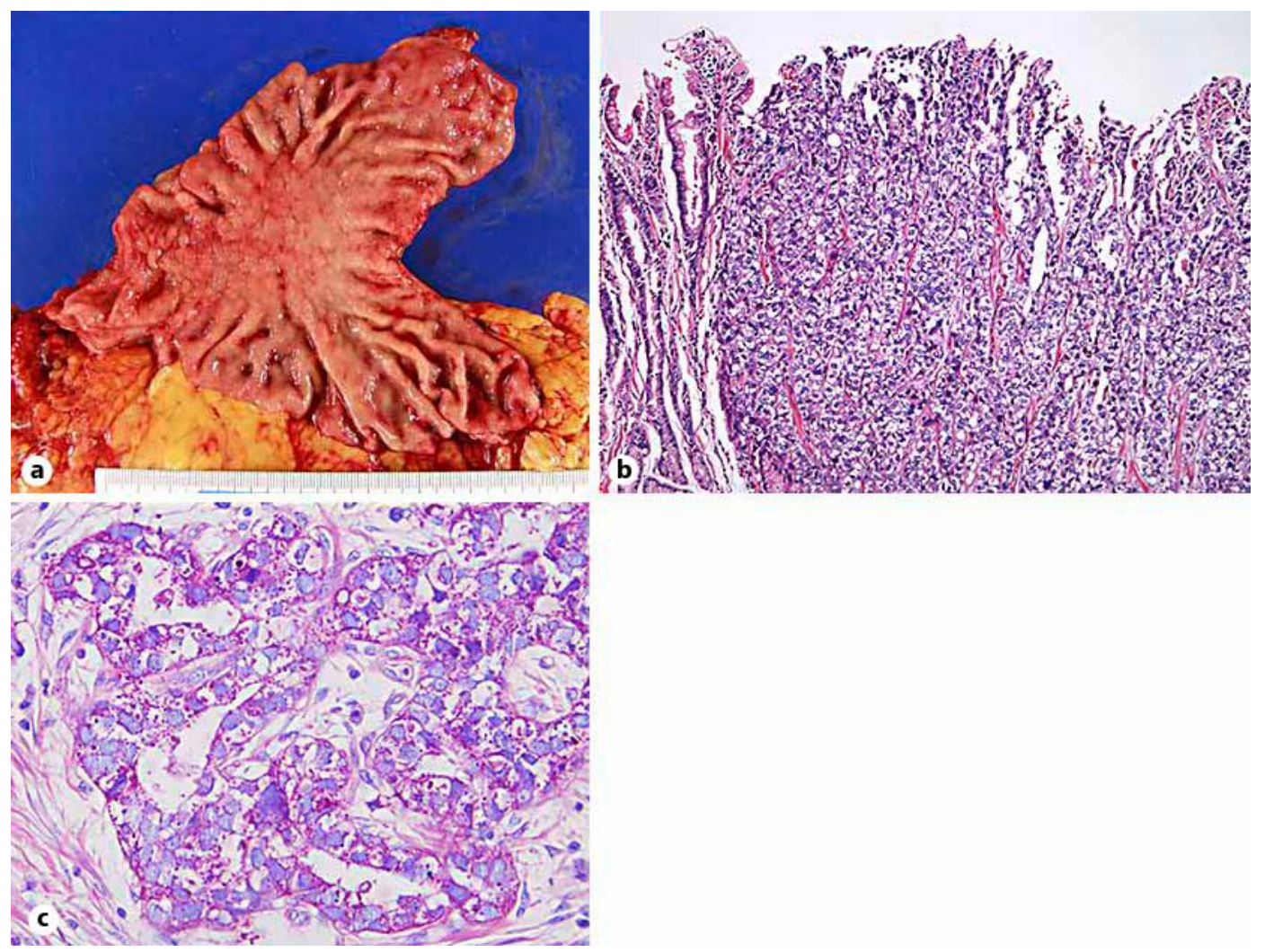

Fig. 1. a Gross appearance of the surgical specimen. The type 2 tumor was located near the pylorus. $\mathbf{b}$ Hematoxylin-eosin staining confirmed the presence of adenocarcinoma with a tubulopapillary growth pattern $(\times 70)$. c PAS stain showed that the clear cytoplasm was almost filled with fine granular glycogen $(\times 280)$. 
Yamabuki et al.: Gastrointestinal Obstruction due to Solitary Lymph Node Recurrence of Alpha-Fetoprotein-Producing Gastric Carcinoma with Enteroblastic Differentiation
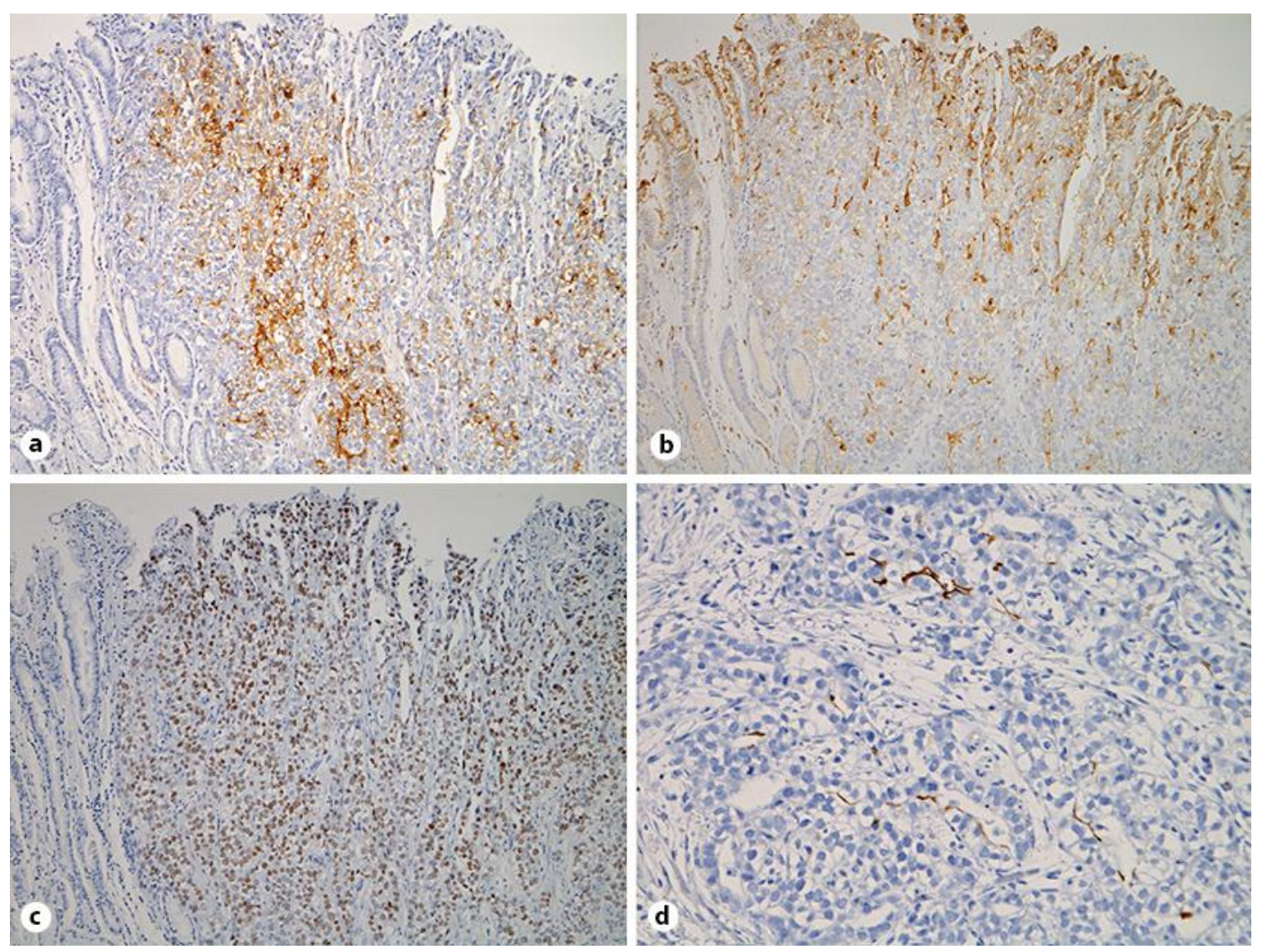

Fig. 2. a Tumor cells were positive for AFP, which was mainly expressed in the cytoplasm of tumor cells $(\times 70)$. b Tumor cells were positive for CEA, which was mainly expressed in the apical surfaces of tumor cells $(\times 70)$. c CDX2 was expressed strongly in the tumor cell nuclei $(\times 70)$. $\mathbf{d}$ CD10 was positive in the luminal surfaces in some tumor cells $(\times 140)$.
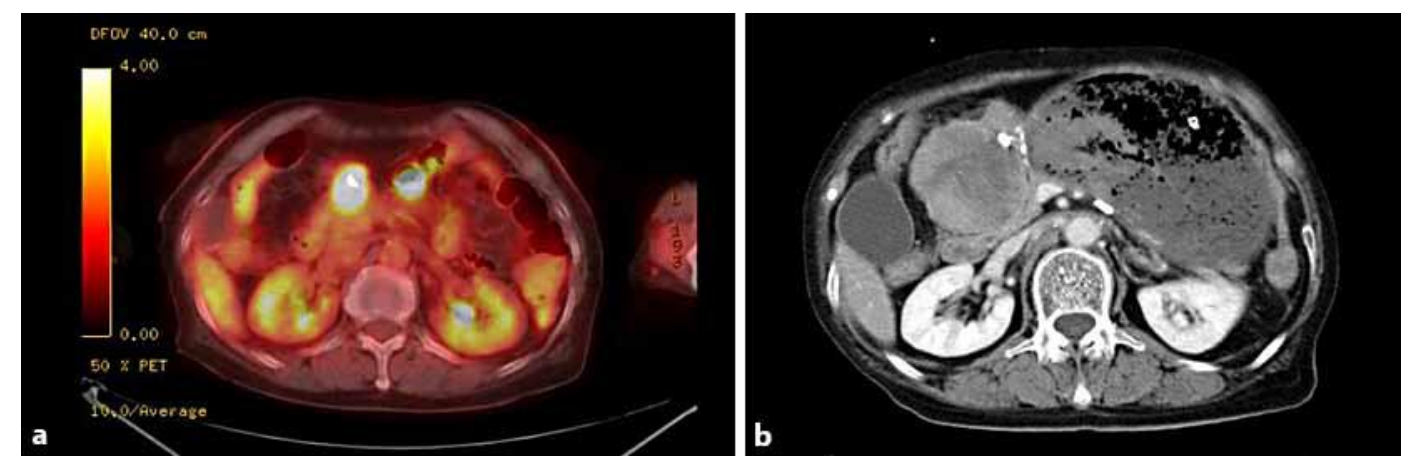

Fig. 3. a FDG-PET confirmed No. 8p lymph node recurrence. b CT revealed gastrointestinal obstruction near the anastomotic site of gastroduodenostomy due to No. 8p lymph node recurrence. 